\title{
SAND99.2988 J
}

Analysis of Hydroperoxides in Solid Polyethylene by MAS ${ }^{13} \mathrm{C}$ NMR and EPR

Roger A. Assink, * Mathew Celina, Timothy D. Dunbar, Todd M. Alam, Roger L. Clough and Kenneth T. Gillen

\section{Department of Organic Materials Sandia National Laboratories Albuquerque, NM 87185-1407}

\section{RECEIVED NOV 291999 \\ OSTI}

\section{Abstract}

${ }^{13} \mathrm{C}$-enriched polyethylene was subjected to $\gamma$-irradiation in the presence of air at 25 and $80^{\circ} \mathrm{C}$ for total doses ranging from 71 to $355 \mathrm{kGy}$. Significant quantities of hydroperoxides were detected in the $25^{\circ} \mathrm{C}$ irradiated sample by ${ }^{13} \mathrm{C}$ magic angle spinning NMR spectroscopy. This method of detection was performed on the solid polymer and required no chemical derivatization or addition of solvent. The chemical stability and subsequent products of the hydroperoxide species were studied by annealing the irradiated samples in air at temperatures ranging from 22 to $110^{\circ} \mathrm{C}$. A time-temperature superposition analysis provided an activation energy of $108 \mathrm{~kJ} / \mathrm{mol}$ for the hydroperoxide decomposition process. The primary products of hydroperoxide decomposition were ketones and secondary alcohols with lesser amounts of acids and esters. EPR measurements suggest that the reactive hydroperoxide species reside in the amorphous phase of polyethylene, consistent with degradation occurring in the amorphous phase.

\section{Introduction}

Hydroperoxides play a key role in the oxidative degradation of many polyolefins, and are believed to be the first product formed during oxidative degradation driven by either thermal, UV or radiative stresses. ${ }^{1-3}$ As degradation continues, the hydroperoxides react to form a variety of secondary products including alcohols, ketones, acids and esters. Characterization of hydroperoxide formation and the subsequent reaction products has proven to be a valuable tool for understanding the aging mechanism of polymers with and without antioxidants. Peroxides are also intentionally introduced into polyethylene and other polyolefins by $\gamma$-irradiation or e-beam treatment of the polymer in the presence of air, as the first step in a graft polymerization process. Subsequent thermal 


\section{DISCLAIMER}

This report was prepared as an account of work sponsored by an agency of the United States Government. Neither the United States Government nor any agency thereof, nor any of their employees, make any warranty, express or implied, or assumes any legal liability or responsibility for the accuracy, completeness, or usefulness of any information, apparatus, product, or process disclosed, or represents that its use would not infringe privately owned rights. Reference herein to any specific commercial product, process, or service by trade name, trademark, manufacturer, or otherwise does not necessarily constitute or imply its endorsement, recommendation, or favoring by the United States Government or any agency thereof. The views and opinions of authors expressed herein do not necessarily state or reflect those of the United States Government or any agency thereof. 


\section{DISCLAIMER}

Portions of this document may be illegible in electronic image products. Images are produced from the best available original document. 
treatment of the peroxide-containing polymer in the presence of a monomer such as acrylonitrile or acrylic acid results in grafting at the sites of radicals formed by the decomposition of the polymeric peroxides. ${ }^{4}$ In this paper we present a study of the generation of hydroperoxides by $\gamma$-irradiation and their subsequent thermal degradation in solid ${ }^{13} \mathrm{C}$-enriched polyethylene by magic angle spinning (MAS) ${ }^{13} \mathrm{C}$ NMR spectroscopy. Because of their importance, methods to detect and quantify hydroperoxides in aged polymers have received considerable attention. The study of hydroperoxides is complicated by their low concentration and their ability to react further under relatively mild conditions. A recent review outlined the various methods that have been developed to study hydroperoxide chemistry in polymers. ${ }^{5}$ The approaches can be classified as either direct or indirect, where indirect requires that the hydroperoxide be chemically derivatized before detection.

The most common indirect approaches are colorimetric methods that depend on either iodometric analysis ${ }^{6}$ or ferrometric complexation. ${ }^{7}$ These colorimetric methods require that the polymer be dissolved or swollen to enable the reactants to diffuse freely throughout the polymer. The elevated temperatures required for the dissolution of many polymers, including polyethylene, lead to further reaction of the hydroperoxides during the experiment. Also the reaction times for complete derivatization have been the subject of some debate and depend on such factors as the film thickness. Indirect methods also include infrared detection of alkyl hydrosulfates after treatment with sulfur dioxide ${ }^{8}$ or of nitrate groups after treatment with nitric oxide. ${ }^{9}$ All of the indirect approaches suffer from the disadvantage of disturbing the sample chemically. Study of the subsequent reactions of hydroperoxide species requires that a new sample be used for each kinetic measurement. Carlsson and Lacoste ${ }^{10}$ have recently provided a critical evaluation of several indirect methods used for measuring hydroperoxide concentrations in oxidized polyolefins.

Direct methods that do not rely on derivatization include infrared and NMR. spectroscopies. Although the weak infrared absorption for isolated hydroperoxides has been observed, $^{11-13}$ the detection of hydrogen-bonded hydroperoxide groups is 
complicated by the overlap of their absorption with that of other hydroxyl groups.

NMR spectroscopy has been used extensively to study scission and crosslinking in polymers subjected to irradiation. ${ }^{17-19}$ The study of oxidative products is less common, although solution state ${ }^{13} \mathrm{C}$ NMR spectroscopy has been used successfully to detect hydroperoxides in dissolved samples of thermally aged polyethylene. ${ }^{20,21}$. Hydroperoxides have also been recently observed by ${ }^{17} \mathrm{O}$ NMR spectroscopy of pentacontane that was thermally aged under ${ }^{17} \mathrm{O}$ enriched molecular oxygen. ${ }^{22}$

We have extended the ${ }^{13} \mathrm{C}$ studies in two ways: first, the use of ${ }^{13} \mathrm{C}$-enriched polyethylene provides an increase in detection sensitivity of nearly two orders-ofmagnitude and second, MAS was employed to eliminate the need to dissolve or swell the sample. In this way we are able to conveniently and directly monitor hydroperoxides and their reaction products in the bulk polymer after radiation and during subsequent annealing experiments. Analysis of the temperature dependence of hydroperoxide decomposition enabled the activation energy of the degradation process to be determined. We have also used electron paramagnetic resonance (EPR) to examine the environment of the hydroperoxide species. EPR cannot directly detect the hydroperoxides in irradiated polymers. It is capable, however, of detecting the radicals which may either be reactants in hydroperoxide formation, or products of hydroperoxide degradation. ${ }^{23}$ Also, photolysis with UV light has previously been employed to create EPR-observable radicals from hydroperoxides in polymers. ${ }^{24,25}$ Thus, EPR is an indirect technique, as the polymer samples must be modified by UV so that hydroperoxide decomposition products can be detected.

\section{Experimental}

Materials. Polyethylene, ${ }^{13} \mathrm{C}$ enriched at $99 \%$, was purchased from Isotec Inc. The DSC analysis showed the main crystalline melting point at $125^{\circ} \mathrm{C}$ confirming a pure highdensity polyethylene.

Radiation Aging. Samples were $\gamma$-irradiated under flowing air conditions at 25 and 80 ${ }^{\circ} \mathrm{C}$ in a ${ }^{60} \mathrm{Co}$ source at a dose rate of approximately $0.74 \mathrm{kGy} / \mathrm{h}$ for times ranging from 4 
to 20 days. The total doses ranged from 71 to $355 \mathrm{kGy}$. Substantial embrittlement of this material was encountered at approximately $200 \mathrm{kGy}$.

Instrumentation. The MAS ${ }^{13} \mathrm{C}$ NMR spectra were recorded on a Bruker AMX-400 spectrometer at $100.6 \mathrm{MHz}$. Samples of approximately $50 \mathrm{mg}$ were packed into $4 \mathrm{~mm}$ rotors and spun at $10 \mathrm{kHz}$. Direct polarization spectra with high power ${ }^{1} \mathrm{H}$ decoupling were recorded with a delay time of $4 \mathrm{~s}$ and typically $256 \mathrm{scans}$. The resonance of the amorphous component of the backbone and all decomposition resonances exhibited complete recovery after $2 \mathrm{~s}$. Spectra with limited numbers of scans were recorded with delay times up to $240 \mathrm{~s}$ in order to quantitatively record the resonance of the crystalline component and to ensure that all decomposition products had fully recovered after a $4 \mathrm{~s}$ delay time. X-and K-band EPR was performed using a Bruker ESP300e spectrometer, each cavity being equipped with an Oxford continuous-flow liquid helium cryostat. UV irradiations were carried out using a $200 \mathrm{~W}$ mercury vapor lamp from Oriel.

\section{Results and Discussion}

Figure 1 shows the ${ }^{13} \mathrm{C}$ MAS NMR spectrum of unaged ${ }^{13} \mathrm{C}$-enriched polyethylene. The two resonances at 33 and $30 \mathrm{ppm}$ correspond to the crystalline and amorphous components, respectively, of the $-\mathrm{CH}_{2}$ - repeat unit in the chain backbone. ${ }^{26}$ The relative proportion of the crystalline and amorphous phases changes modestly during $\gamma$-irradiation and will be the subject of a later publication. The resonance at $133 \mathrm{ppm}$ corresponds to a spinning side band of the chain backbone. Although the intensity of the amorphous component is greater than that of the crystalline component in the central resonance, the situation is reversed for the spinning side band resonance. The amorphous resonance is not expected to contribute as much to the spinning side band manifold because its spectrum is narrowed to a greater degree by chain motions. Small resonances at 14 and $11 \mathrm{ppm}$ are visible on the spectrum that has been vertically expanded by a factor of 50. These resonances, which each comprise less than $0.1 \%$ of the total intensity, correspond to methyl end groups and methyl groups on isolated ethyl branches,

respectively. ${ }^{27}$ The small resonance at $175 \mathrm{ppm}$ corresponds to a high field spinning side band that has been reflected into the spectrum. 
The spectra of ${ }^{13} \mathrm{C}$-polyethylene samples that were exposed to 7 days of $\gamma$ radiation in the presence of air at 25 and $80^{\circ} \mathrm{C}$ are shown in Figure 2. Each spectrum has been expanded vertically by a factor of 50 . The $80^{\circ} \mathrm{C}$ sample exhibits increased noise levels because the sample size was smaller. The linewidth of the $-\mathrm{CH}_{2}$ - backbone unit has increased somewhat for the $25^{\circ} \mathrm{C}$ sample and has increased significantly for the 80 ${ }^{\circ} \mathrm{C}$ sample. This increase is attributed to contributions from carbons that are $\beta$-position relative to the oxidative products. Each spectrum exhibits the original resonances discussed in the preceding paragraph and in addition has resonances at $72,85,172-184$, and $207 \mathrm{ppm}$ corresponding to the primary oxidative degradation products. These resonances have been previously assigned to secondary alcohols, hydroperoxides, acid and esters, and ketones, respectively. ${ }^{20,21}$ Minor resonances at 81, 99 and 194 ppm have been identified as a dialkyl peroxide, ${ }^{28}$ a vinyl carbon and an aldehyde. The intensities of these resonances are much less than those of the primary degradation products. Because they cannot be accurately measured, these minor resonances will not be discussed further in this paper.

The general features of the primary degradation products for the two temperatures are similar with two exceptions. First, the concentration of degradation products at $80^{\circ} \mathrm{C}$ is much higher than that at $25^{\circ} \mathrm{C}$. Second, while the spectrum of the sample irradiated at $25^{\circ} \mathrm{C}$ has a distinct resonance at $85 \mathrm{ppm}$ corresponding to hydroperoxides, this resonance is not observed for the sample irradiated at $80^{\circ} \mathrm{C}$. Since the hydroperoxide is a reactive intermediate, this second observation is not surprising. We will show later that the halflife for the decay of hydroperoxide species at $80^{\circ} \mathrm{C}$ in this material is approximately 6 hours. Thus, while considerable amounts of hydroperoxide species should have been produced, most of them would have quickly undergone further reactions during the radiation process.

The spectra were recorded by direct polarization experiments under conditions for which the degradation and amorphous phase resonances were completely recovered. The relative concentrations of the various functional groups were determined by peak integration. These concentrations were adjusted downward by a factor of 1.22 to account for incomplete relaxation of the crystalline phase as determined from spectra recorded 
with a $240 \mathrm{~s}$ delay time. The results for radiation exposure at 25 and $80^{\circ} \mathrm{C}$ are shown in Figures $3 \mathrm{a}$ and $3 \mathrm{~b}$. The concentration of hydroperoxide species formed at $25^{\circ} \mathrm{C}$ increases rapidly for short irradiation times, but then levels off and decreases significantly between 11 and 20 days. This behavior is characteristic of a reactive intermediate. The concentration of secondary alcohols is the smallest of the three primary degradation products for samples aged at both 25 and $80^{\circ} \mathrm{C}$. The concentration of ketones is comparable to that of acids and esters at $25^{\circ} \mathrm{C}$. At $80^{\circ} \mathrm{C}$ the concentration of acids and esters is low initially but then increases until their concentration surpasses that of ketones for long aging times.

In addition to observing the formation of hydroperoxides, we are able to investigate the decomposition chemistry of these reactive species during subsequent thermal exposure. Figure 4 shows the hydroperoxide region of the sample radiatively aged for 7 days at $25^{\circ} \mathrm{C}$. The sample was then heated at $110^{\circ} \mathrm{C}$ in air for the times indicated, returned to room temperature and its spectrum recorded. The intensity of the hydroperoxide resonance decreases rapidly as a function of annealing time. Additional samples that had also been radiatively aged for 7 days at $25^{\circ} \mathrm{C}$ were annealed for various times at 95,80 and $65^{\circ} \mathrm{C}$. The hydroperoxide concentrations were difficult to accurately quantify because of the broadness of the resonances and the uneven baselines. In addition, the hydroperoxide resonance overlaps somewhat with a smaller unidentified resonance at $81 \mathrm{ppm}$. For these reasons, each spectrum was phased identically so that its baseline features were similar. Peak heights rather than peak areas of the hydroperoxide resonances were then measured. The annealing process was continued until the spectrum exhibited no change after additional annealing time. The normalized peak heights versus annealing times for the various annealing temperatures are shown in Figure 5a. Also shown in Figure 5a is a single measurement of the hydroperoxide concentration in a sample that had been stored at ambient laboratory conditions for 6 months.

The first half of the decomposition curve at each temperature was used to calculate a rate constant assuming first order kinetics. A least squares fit of the data provided rates of $3.7 \times 10^{-4}, 0.72 \times 10^{-4}, 0.20 \times 10^{-4}$ and $0.048 \times 10^{-4} \mathrm{~s}^{-1}$ at $110,95,80$ and $65{ }^{\circ} \mathrm{C}$ respectively. These rates can be compared to those measured by $\mathrm{Chien}^{29}$ for the 
decomposition of hydroperoxides in low-density polyethylenes. In those studies the hydroperoxides were prepared by low-temperature autooxidation initiated by AIBN and the degradation rates measured at 100,120 and $135^{\circ} \mathrm{C}$. An interpolation of our results predicts that the rate constant at $100^{\circ} \mathrm{C}$ is $1.32 \times 10^{-4} \mathrm{~s}^{-1}$ compared to an average value of $0.32 \times 10^{-4} \mathrm{~s}^{-1}$ reported by Chien. We believe that this difference is not unreasonable considering the difference in materials and in the method used to generate the hydroperoxide species. Degradation rates are known to depend on local conditions and the distribution of hydroperoxide species. Chien also reported that from 0 to $15 \%$ of the hydroperoxides decayed at a rate approximately an order of magnitude slower than the initial rate. Our sensitivity at long reaction times, during which the hydroperoxide resonance is merging with the baseline, is insufficient to detect evidence for this behavior.

The temperature dependence (activation energy) of hydroperoxide decomposition was calculated by the time-temperature superposition method. ${ }^{30,31}$ The advantage of this approach is that it utilizes all of the data from each temperature experiment and does not require definitive knowledge of the underlying kinetic behavior (i.e. $1^{\text {st }}$ or $2^{\text {nd }}$ order kinetics). We first select the lowest temperature, $22^{\circ} \mathrm{C}$, as the reference temperature, $T_{\text {ref. }}$ If increasing the temperature to $T$ equally accelerates all of the reactions underlying the oxidation, then the time behavior of the decomposition will be accelerated by a constant multiplicative shift factor, a . For each higher temperature, we empirically determine the value of $a_{T}$ that results in the best superposition with the data at $T_{\text {ref. }}$. Figure $5 \mathrm{~b}$ shows the superimposed results for the decomposition of the hydroperoxide species. Figure 6 shows the shift factors, on a logarithmic scale, plotted versus inverse temperature. We observe Arrhenius behavior of $\log \left(\mathrm{a}_{\mathrm{T}}\right)$ versus inverse temperature and calculate an activation energy of $108 \mathrm{~kJ} / \mathrm{mol}(25.7 \mathrm{kcal} / \mathrm{mol})$ for this process. The shift factor for hydroperoxide decomposition at $22^{\circ} \mathrm{C}$ was given one-third the weight of the shift factors for the elevated temperatures since the complete decomposition curve was not measured at this temperature. We had earlier reported an activation energy of 98 $\mathrm{kJ} / \mathrm{mol}$ that did not utilize the decomposition data obtained at $22{ }^{\circ} \mathrm{C}$. 
Figure 7 shows selected portions of the difference spectrum in which the spectrum of the 7 day radiatively aged sample without annealing was subtracted from the spectrum of the same sample after it had been annealed for 2 hours at $110^{\circ} \mathrm{C}$. These conditions correspond to nearly complete elimination of the hydroperoxide resonance (see Figures 4 $\& 5 a)$. The reduction in the hydroperoxide concentration is depicted by the inverted resonance at $85 \mathrm{ppm}$. The production of ketones, acids and esters, and alcohols is depicted by additional intensity at their respective positions. This figure illustrates that in . the presence of air, the disappearance of a unit intensity of hydroperoxide species results in an increase of two to three times that intensity in the resonances of the product species. Obviously, further oxidation is occurring during the annealing process.

The chemical mechanisms for the degradation of hydroperoxide species can be classified into four stages: initiation, propagation, branching and termination. ${ }^{33}$ The initiation stage yields both alkoxy and hydroxyl radicals. These radicals rapidly abstract hydrogen atoms to form alcohols and water:

$$
\begin{aligned}
& \mathrm{RO} \bullet+\mathrm{RH} \rightarrow \mathrm{R} \bullet+\mathrm{ROH} \\
& \mathrm{HO} \bullet+\mathrm{RH} \rightarrow \mathrm{R} \bullet+\mathrm{H}_{2} \mathrm{O} .
\end{aligned}
$$

When oxygen is available, as in these experiments, the alkyl radicals can form peroxy radicals that undergo a propagation step:

$$
\begin{aligned}
& \mathrm{R} \bullet+\mathrm{O}_{2} \rightarrow \mathrm{RO}_{2} \bullet \\
& \mathrm{RO}_{2} \bullet+\mathrm{RH} \rightarrow \mathrm{RO}_{2} \mathrm{H}+\mathrm{R} \bullet
\end{aligned}
$$

A scission step involving alkoxy radicals can yield an aldehyde or ketone, while a bimolecular termination step involving two peroxy radicals yields alcohols and ketones. Additional experiments comparing rates and product distributions with and without oxygen are being performed.

We have also used EPR to study both enriched and non-enriched polyethylene samples that were irradiated at $25^{\circ} \mathrm{C}$. These experiments were conducted to determine the type and relative amounts of radicals that exist after irradiation and to characterize the environment of the hydroperoxide species based upon the radical species observed after UV photolysis of the irradiated sample. 
We initially (a month after irradiation) observed a large singlet $(g=2.0045)$ superimposed upon a multiple line spectrum of low intensity. This multiple line spectrum decayed and was not observable after several more weeks' time. We assign such a signal to the alkyl radical, ${ }^{34}$ though at the time of our observation its signal was weak and partially obscured by the large singlet, so there may be some contribution from the allyl radical. ${ }^{35}$ This is consistent with previous observations of long lived alkyl and allyl radicals in irradiated polyethylene, thought to be in crystalline or interfacial regions. $^{36}$ Additionally, singlet signals have been observed previously in air-irradiated polyethylene and have been assigned to either peroxy ${ }^{36}$ or polyenyl ${ }^{37}$ radicals. We believe the singlet we observe results from polyenyl and not from peroxy radicals for several reasons. First, the signal we observe in either X- or K-band $(9.4$ and $24.0 \mathrm{GHz}$, respectively) is strongly power dependent, suggesting that the spin-lattice relaxation time is much more like that of a carbon-based radical rather than an oxygen-based radical. ${ }^{23}$ Second, we observe a marked dependence of the peak width upon whether we are observing irradiated polyethylene with a normal abundance of ${ }^{13} \mathrm{C}\left(\Delta H_{\mathrm{pp}}=5.9 \mathrm{G}\right)$ or that which is enriched to $99 \%{ }^{13} \mathrm{C}\left(\Delta H_{\mathrm{pp}}=12.7 \mathrm{G}\right)$. This change in peak width indicates that the unpaired electron causing the singlet is interacting primarily with carbon atoms. The unpaired electron of a peroxy radical is localized on the peroxy's terminal oxygen, and would therefore have little interaction with the carbon to which the peroxy is attached. Upon cooling the irradiated polyethylene sample and employing low microwave power, no $g$-value anisotropy was observed, contrasting with observations typical of peroxy radicals in polyethylene. ${ }^{38}$ Consequently, we assign the singlet to the polyenyl radical.

At room temperature, X-band spectra of non-enriched irradiated polyethylene show only a singlet after exposure to air for at least a month, while K-band spectra also show a small signal at $g \sim 2.009$. Because this signal is at a higher $g$-value than the polyenyl radical, and is not susceptible to power saturation, we assign it to the peroxy radical. The double integrals of the two signals (taken at low power to avoid saturating the polyenyl radical) are in the ratio of approximately 1000 polyenyl to 1 peroxy. 
Comparing the double integral of the polyenyl signal to that of weak pitch, we calculate approximately $10^{16}$ polyenyl and $10^{13}$ peroxy radicals per gram of polyethylene.

In order to investigate the environment of the hydroperoxides, we have used UV photolysis to cleave the hydroperoxides and have studied the decay characteristics of the resulting radicals by EPR. ${ }^{24,25}$ To avoid seeing an EPR signal that is dominated by the polyenyl radical background, we operate at high power $(20 \mathrm{~mW})$ so that these radicals are saturated. $^{23,39}$ Figure 8 shows EPR spectra, recorded at $50 \mathrm{~K}$, of the sample which had been $\gamma$-irradiated for 7 days at $25^{\circ} \mathrm{C}$. Spectrum 8 a, taken before UV exposure, is a mixture of peroxy and power-saturated polyenyl radicals. Upon exposure to UV light, spectrum $8 \mathrm{~b}$, the hydroperoxides have been cleaved to alkoxy and hydroxy radicals, quickly resulting in the formation of peroxy radicals via $\mathrm{H}$ abstraction and participation of oxygen. ${ }^{40}$ Further evidence that the radicals we observe are peroxy and not alkoxy is garnered from the fact that alkoxy $g_{1}$ values $(2.03-2.11)$ are generally well above the $g_{1}$ values observed here (see below). ${ }^{41}$ The UV irradiation was for 30 minutes at a power on the order of $0.01-0.1 \mathrm{~W} / \mathrm{cm}^{2}$ at the sample. For clarity, we have included spectrum $8 \mathrm{e}$, which is obtained by subtracting the spectrum acquired before UV-irradiation from that acquired immediately after UV-irradiation. Spectrum 8e clearly shows the rhombic nature of the nonrotating peroxy radical's $g$-values, with $g_{1}=2.026, g_{2}=2.011$, and $g_{3}=2.003$. ${ }^{42}$ We note that the signal near $g=2.026$ (peroxy) shifts to slightly higher $g$ value after irradiation. Spectrum $8 \mathrm{c}$ shows that annealing for one hour at room temperature is sufficient to cause most of the radicals originating from the UV-cleaved peroxides to decay. After annealing for three days at room temperature, spectrum $8 \mathrm{~d}$, the signal is nearly the same as before UV irradiation. Therefore we believe that the peroxy radicals observed after UV irradiation reside in the amorphous regions of polyethylene. Their decay is much more rapid at room temperature than either the polyenyl or already existing peroxy radicals, which are thought to be in either crystalline or interfacial environments. $^{36,43}$ This decay rate of the UV-generated peroxy radicals is approximately that reported for peroxy radicals generated in amorphous regions of 
polyethylene. $^{23}$ In summary, the EPR data is consistent with the formation of hydroperoxides in the amorphous phase.

\section{Conclusions}

We have shown that the hydroperoxide species in $\gamma$-irradiated ${ }^{13} \mathrm{C}$-polyethylene can be directly monitored by MAS ${ }^{13} \mathrm{C}$ NMR spectroscopy. The experiments were performed without the need for special sample preparation such as chemical derivatization or dissolution. Annealing experiments demonstrated that the hydroperoxide species are thermally unstable and illustrated why this species was not observed in the sample irradiated at $80^{\circ} \mathrm{C}$. We could readily observe the disappearance of the peroxide resonance and the simultaneous growth of product resonances corresponding to alcohols, ketones and acids/esters. A combination of propagation, chain branching, and termination steps are required to account for the distribution of product species. An activation energy for peroxide decomposition of $108 \mathrm{~kJ} / \mathrm{mol}$ was calculated from annealing data gathered at a series of temperatures. EPR spectroscopy suggests that residual polyenyl and a very low concentration of peroxy radicals are predominately trapped in interfacial or crystalline regions. Peroxy radicals observed after UVphotolysis of hydroperoxides are in amorphous regions, consistent with degradation occurring in the amorphous phase.

\section{Acknowledgments}

Sandia is a multiprogram laboratory operated by Sandia Corporation, a Lockheed Martin Company, for the United States Department of Energy under Contract DE-AC0494AL85000. 


\section{References}

1. Emanuel, N. M.; Denisov, E. T.; Maizus, Z. K. Liquid-Phase Oxidation of Hydrocarbons; Plenum Press: New York, 1967.

2. Scott, B. Atmospheric Oxidation and Antioxidants; Elsevier: Amsterdam, 1965.

3. Clough, R. L.; Billingham, N. C.; Gillen, K. T. Polymer Durability, Degradation, Stabilization, and Lifetime Prediction; Clough, R. L.; Billingham, N. C.; Gillen, K. T., Ed; American Chemical Society: Washington, DC, 1996; Vol. 249, pp 712.

4. Charlesby, A. Atomic Radiation and Polymers; Pergamon Press: New Your, 1960, pp 397.

5. Scheirs, J.; Carlsson, D. J.; Bigger, S. W. Polym.-Plast. Technol. Eng. 1995, 34, 97.

6. Heaton, F. W.; Uri, N.; J. Sci. Food Agr. 1958, 9, 781.

7. Zeppenfeld, G. Makromol. Chem. 1966, 90, 169.

8. Mitchell, J. Jr.; Perkins, L. R. Appl. Polym. Sym. 1967, 4, 167.

9. Carlsson, D. J.; Brousseau, R.; Zhang, C.; Wiles, D. M. Polym. Deg. Stab. 1987, 17, 303.

10. Carlsson, D. J.; Lacoste, J. Polym. Deg. Stab. 1991, 32, 377.

11. Luongo, J. P. Appl. Polym. Sci. 1960, 3, 302.

12. Luongo, J. P. J. Polym. Sci. 1960, 42, 139.

13. Tabankia, M. H.; Philippart, J. L.; Gardette, J. L. Polym. Deg. Stab. 1985, 12, 349.

14. Klemchuk, R. P.; Horng, P. L. Polym. Deg. Stab. 1984, 7, 131.

15. Lacoste, J.; Carlsson, D. J. J. Polym. Sci. Polym. Chem. Ed. 1992, 30, 493.

16. Lacoste, J.; Vaillant, D.; Carlsson, D. J. J. Polym. Sci. Polym. Chem. Ed. 1993, $31,715$.

17. Hill, D. J. T.; O’Donnell, J. H.; Perera, M. C. S.; Pomery, P. J. Radiat. Phys. Chem. 1992, 40, 127.

18. O'Donnell, J. H.; Whittaker, A. K. Polymer, 1992, 33, 62.

19. O'Donnell, J. H.; Whittaker, A. K. J. Polym. Sci., Polym. Chem. Ed. 1992, 30, 185.

20. Cheng, H. N.; Schilling, F. C.; Bovey, F. A. Macromolecules 1976, 9, 363. 
21. Jelinski, L. W.; Dumais, J. J.; Luongo, J. P.; Cholli, A. L. Macromolecules 1984, 17,1650 .

22. Alam, T. M.; Celina, M.; Assink, R. A.; Clough, R. L.; Gillen, K. T.; Wheeler, D. R. Macromolecules submitted.

23. Ohnishi, S.I.; Sugimoto, S.I.; Nitta, I. J. Polym. Sci. , Part A: Polym. Chem. 1963, 1,605 .

24. Chien, J. C. W.; Boss, C. R. J. Am. Chem. Soc. 1967, 89, 571.

25. Faucitano, A.; Buttafava, A.; Martinotti, F.; Gratani, F.; Bortolus, P. J. Polym. Sci. , Polym. Chem. Ed. 1985, 23, 635.

26. Tonnelli, A. E. NMR Spectroscopy of Polymers; Ibbett, R. N., Ed; Blackie Academic \& Professional: Glasgow, 1993, pp 161.

27. Randall, J. C.; Zoepfl, F. J.; Silverman, J. NMR and Macromolecules; Randall J. C. Jr., Ed; American Chemical Society: Washington, DC, 1984; Vol. 247, pp 245.

28. Aganov, A. V.; Antonovskii, V. L. Izv. Akad. Nauk SSSR, Ser. Khim. 1982, 2, 271.

29. Chien, J. C. W. J. Polym. Sci. Pt A-1 1968, 6, 375.

30. Ferry, J. D. Viscoelastic Properties of Polymers, John Wiley and Sons: New York, 1980.

31. Gillen, K. T.; Celina, M.; Clough, R. L.; Wise J. Trends in Polymer Science, 1997, 5, 250.

32. Assink, R. A.; Celina, M.; Dunbar T. M.; Alam, T. M.; Clough, R. L.; Gillen, K. T. Polym. Prepr., submitted.

33. MacCallum, J. R. Developments in Polymer Degradation - 6, Grassie, N., Ed; Elsevier Applied Science Publishers: London, 1985, pp191.

34. Libby, D.; Ormerod, M.G.; Charlesby, A. Polymer 1960, 1, 212.

35. Ohnishi, S.I.; Sugimoto, S.I.; Nitta, I. J. Chem. Phys. 1962, 37, 1283.

36. O'Neill, P.; Birkinshaw, C.; Leahy, J.J.; Barklie, R. Polym. Degrad. Stab. 1999, 63,31 .

37. Jahan, M.S.; McKinny, K.S. Nucl. Instrum. Methods Phys. Res., Sect. B 1999, $151,207$. 
38. Jahan, M.S.; Wang, C.; Schwartz, G.; Davidson, J.A. J. Biomed. Mater. Res. 1991, 25, 1005.

39. Hori, Y.; Shimada, S.; Kashiwabara, H. Polymer 1977, 18, 151.

40. Iley, J.; Taylor, P.G. The Chemistry of Hydroxyl, Ether and Peroxide Groups;

Patai, S., Ed.; Wiley: New York, 1993; p 263 and references therein.

41. Box, H.C.; Budzinski, E.E.; Freund, H.G. J. Chem. Phys. 1984, 81, 4898.

42. Schlick, S.; Kevan, L. J. Am. Chem. Soc. 1980, 102, 4622.

43. Lawton, E.J.; Powell, R.S.; Balwit, J.S. J. Polym. Sci. 1958, 32, 277. 


\section{Figure Captions}

Figure 1 The ${ }^{13} \mathrm{C}$ MAS NMR spectrum of unaged ${ }^{13} \mathrm{C}$-polyethylene showing the crystalline and amorphous components of the main chain. SSB = spinning side band.

Figure 2 The ${ }^{13} \mathrm{C}$ MAS NMR spectra of ${ }^{13} \mathrm{C}$-polyethylene $\gamma$-irradiated for 7 days at 25 and $80^{\circ} \mathrm{C}$. Resonances corresponding to ketones, acids, esters, hydroperoxides and alcohols are identified.

Figure 3 The distribution of functional groups vs.irradiation time at 25 and $80^{\circ} \mathrm{C}$. The percents shown represent the percent carbons associated with each degradation species compared to the total carbon population.

Figure 4 The ${ }^{13} \mathrm{C}$ MAS NMR spectra of ${ }^{13} \mathrm{C}$-polyethylene annealed at $110^{\circ} \mathrm{C}$ for the times indicated. The sample had originally been exposed to $\gamma$-radiation for 7 days at $25^{\circ} \mathrm{C}$.

Figure 5 (a) Normalized peak heights of the hydroperoxide resonance as a function of annealing time at temperatures ranging from 22 to $110^{\circ} \mathrm{C}$. The sample had originally been exposed to $\gamma$ radiation for 7 days at $25^{\circ} \mathrm{C}$. (b) The timetemperature superposition of the normalized peak heights at a reference temperature of $22^{\circ} \mathrm{C}$.

Figure 6 Arrhenius plot of the shift factors for loss of hydroperoxide species during thermal annealing. The activation energy is $108 \mathrm{~kJ} / \mathrm{mol}$.

Figure 7 The spectrum of the sample which had been radiatively aged at $25^{\circ} \mathrm{C}$ for 7 days was subtracted from the spectrum of the same sample after it had been annealed for 2 hours at $110^{\circ} \mathrm{C}$. Portions of the difference spectrum show the loss of hydroperoxides and formation of ketones, acids, esters and alcohols attributed to the annealing process.

Figure 8 Creation of peroxy radicals in $\gamma$-irradiated polyethylene by UV cleavage of hydroperoxides. All EPR spectra were taken at a microwave power of $20 \mathrm{~mW}$ and temperature of $50 \mathrm{~K}$. (a) Spectrum of the polyenyl radicals and the already-existing peroxy radical in the $\gamma$-irradiated sample. (b) Spectrum of the peroxy radicals created after in-situ UV illumination. (c) Spectrum of the sample after annealing for $1 \mathrm{~h}$ at RT. (d) Spectrum of the sample after annealing for 3 days at RT. The signal has returned to its pre-irradiated state. (e) Spectrum of "a" subtracted from " $b$ " and a computer simulation (dotted line) used to discern the $g$-values of the observed peroxy radical, $g_{1}=2.026$, $g_{2}=2.011, g_{3}=2.003$. 


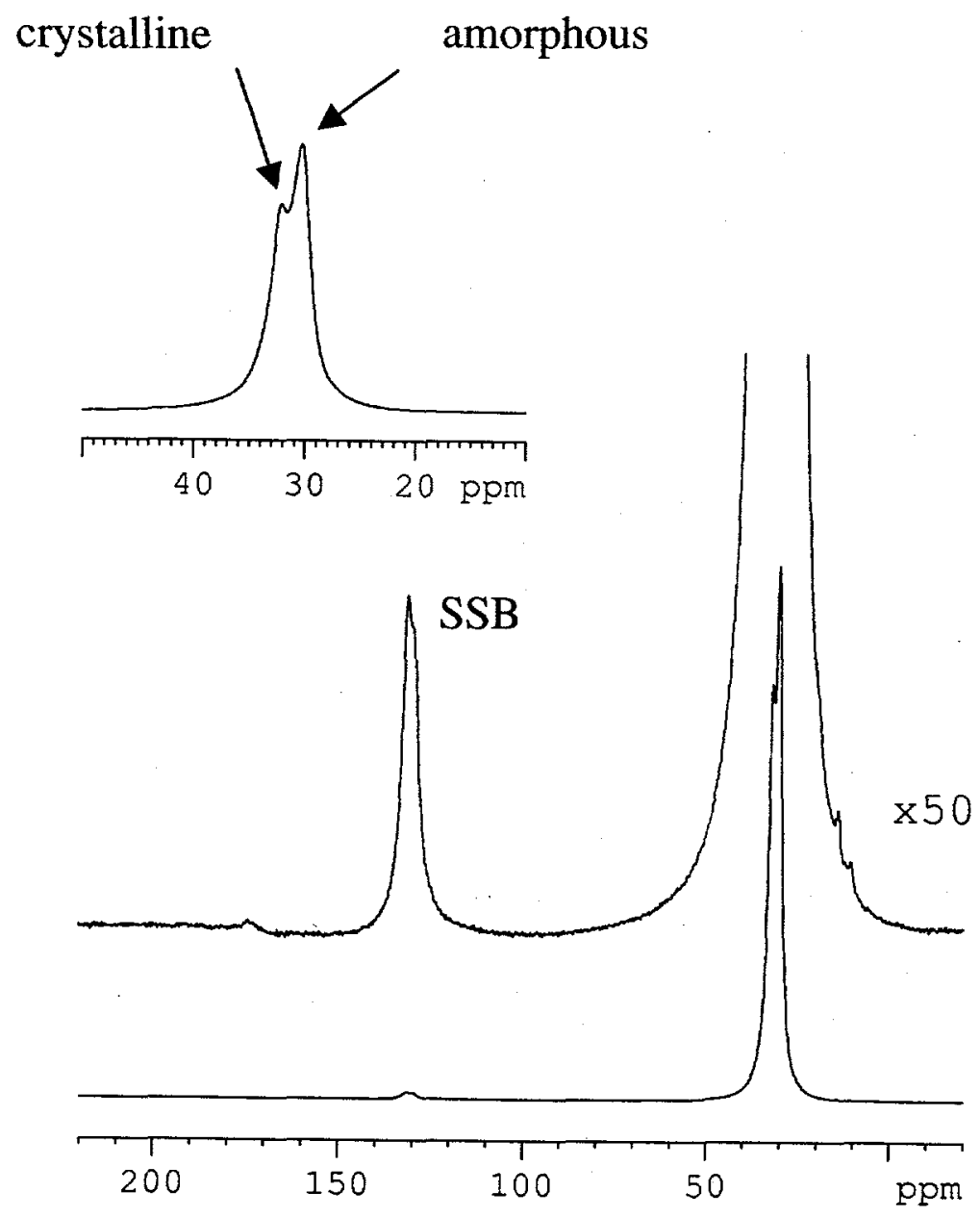




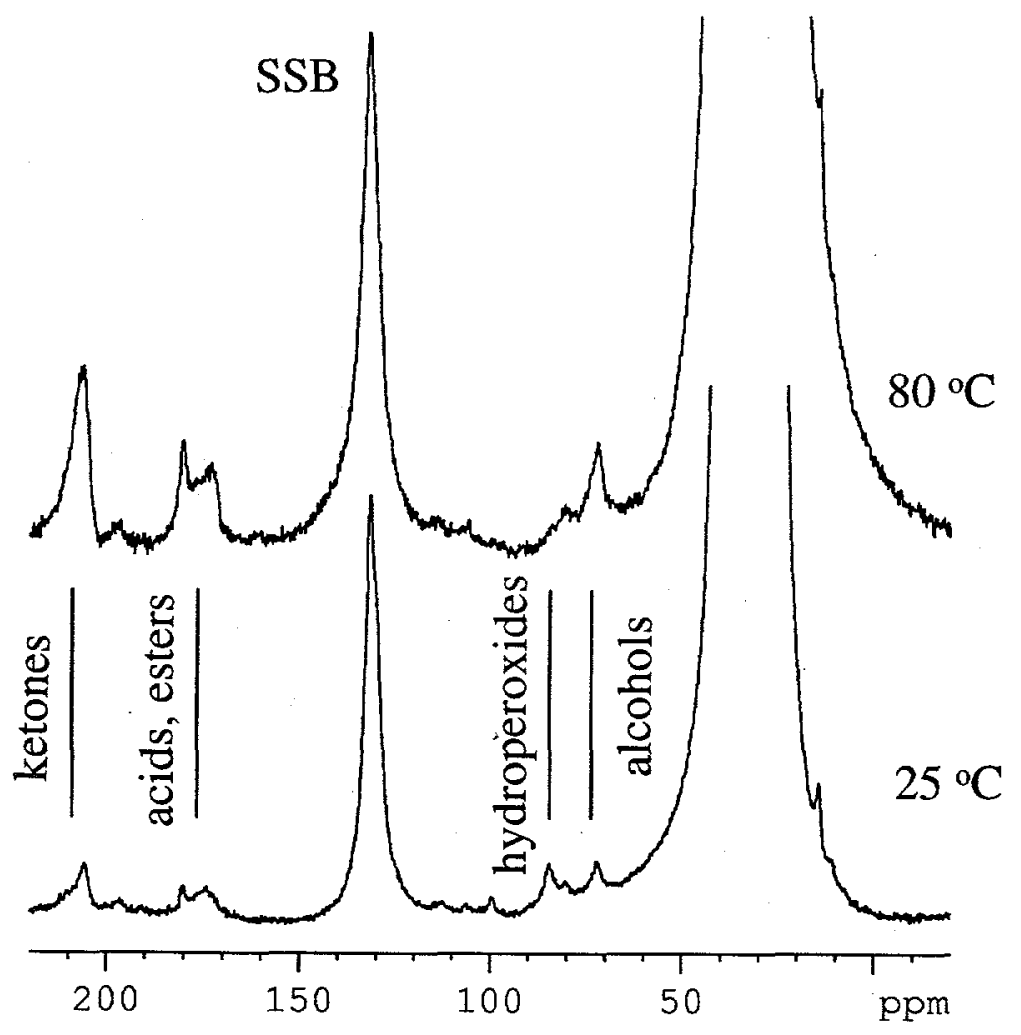

Fis 2 


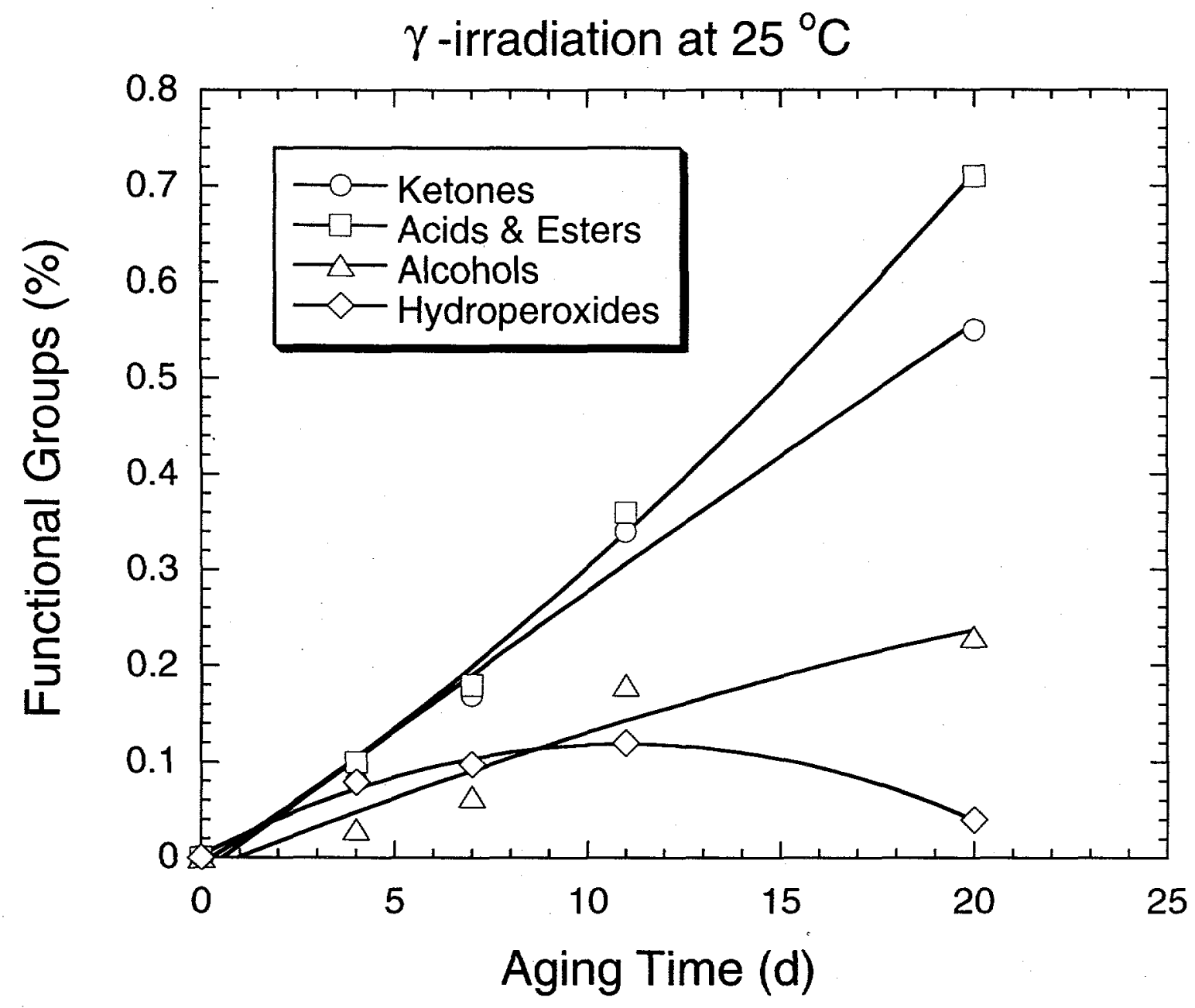

Figja 


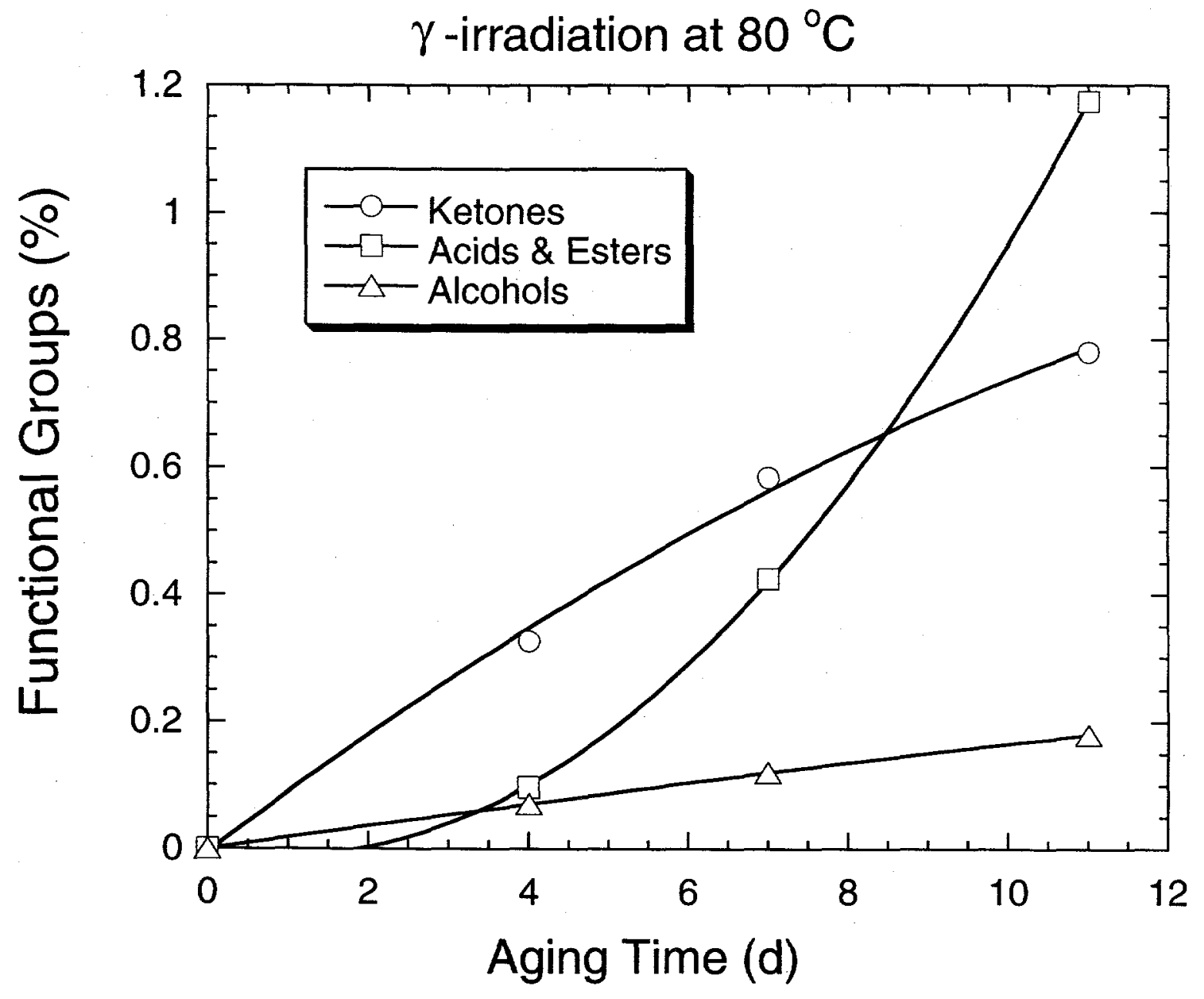

Fis3b 

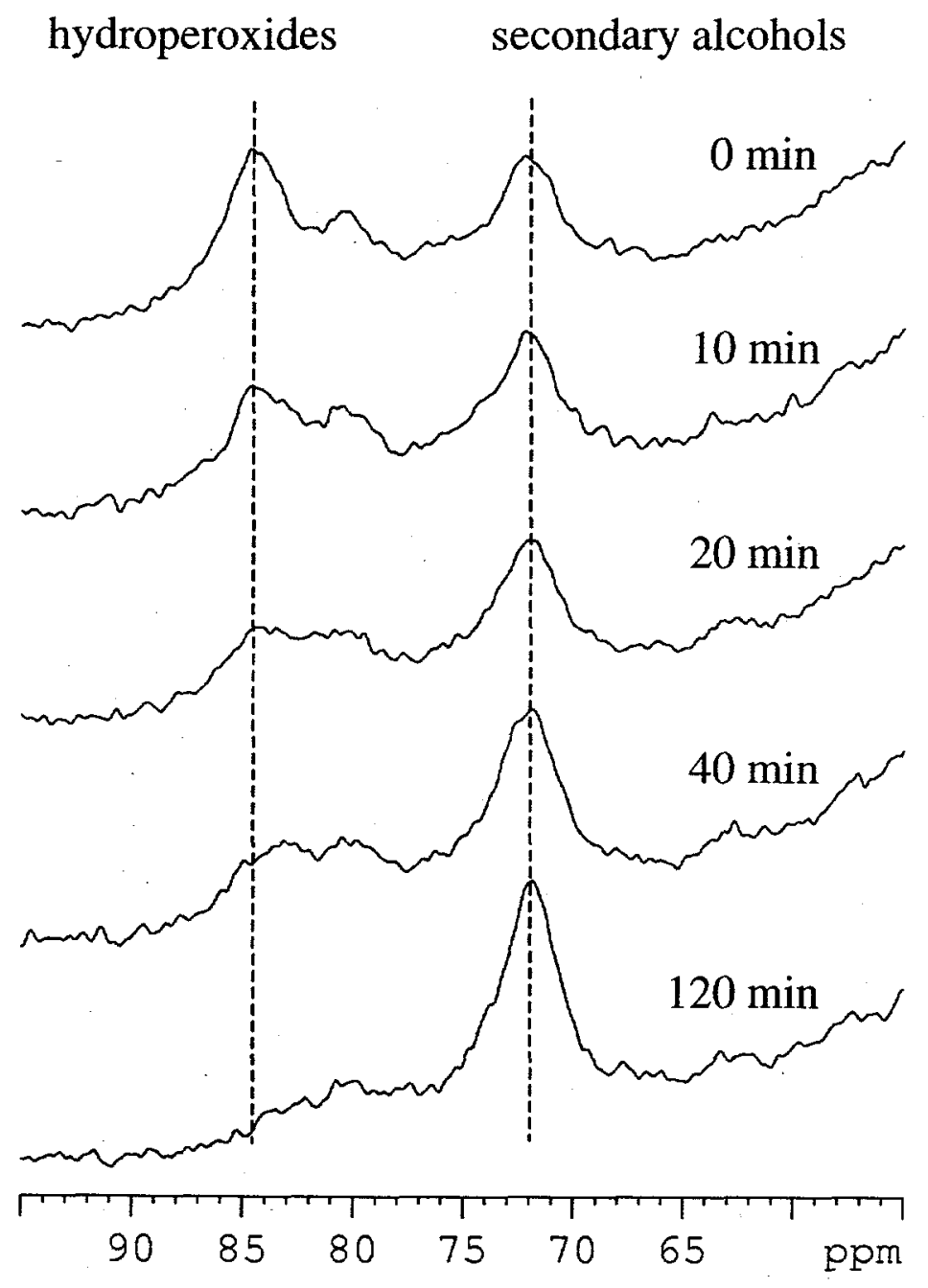


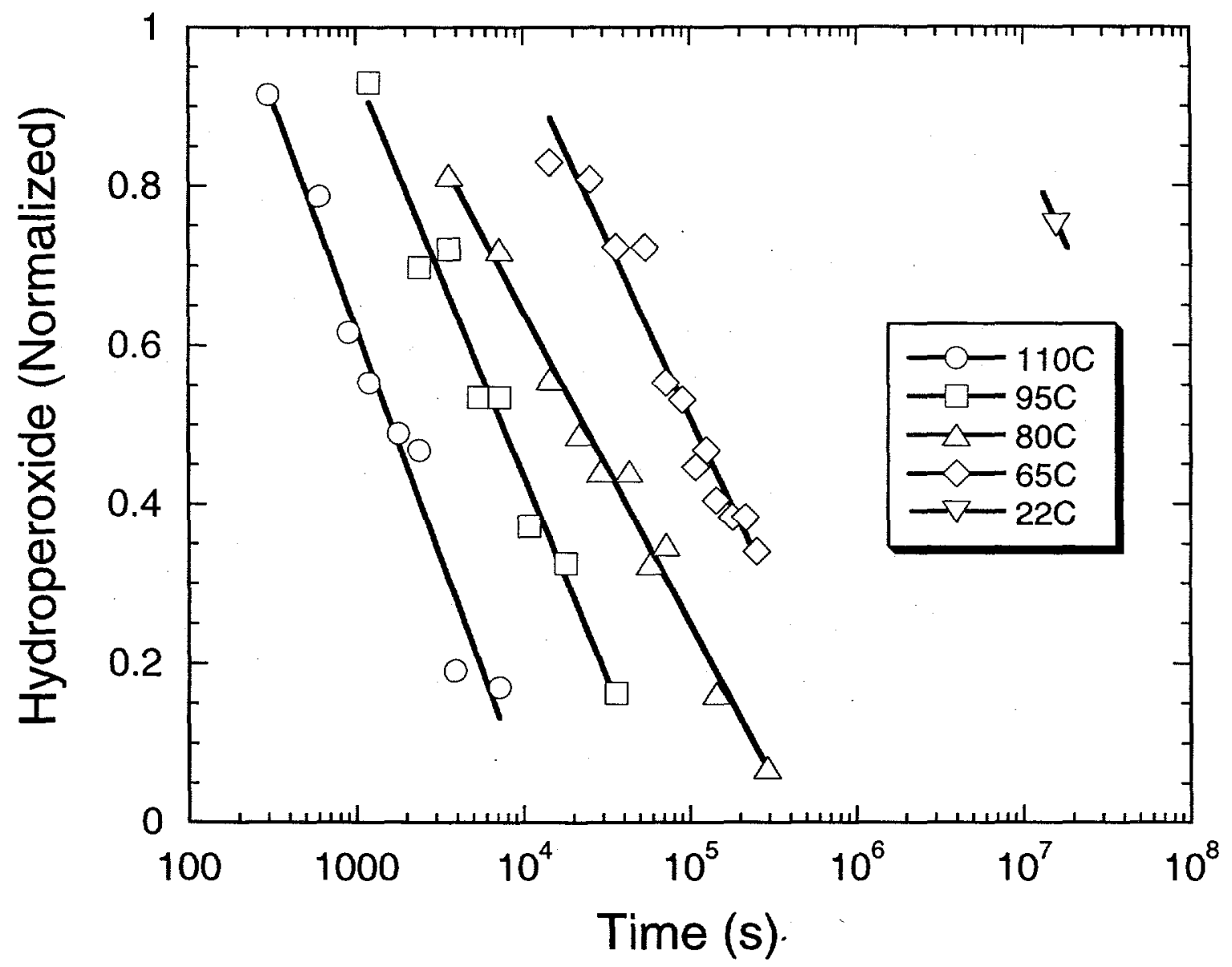

$5 a$ 


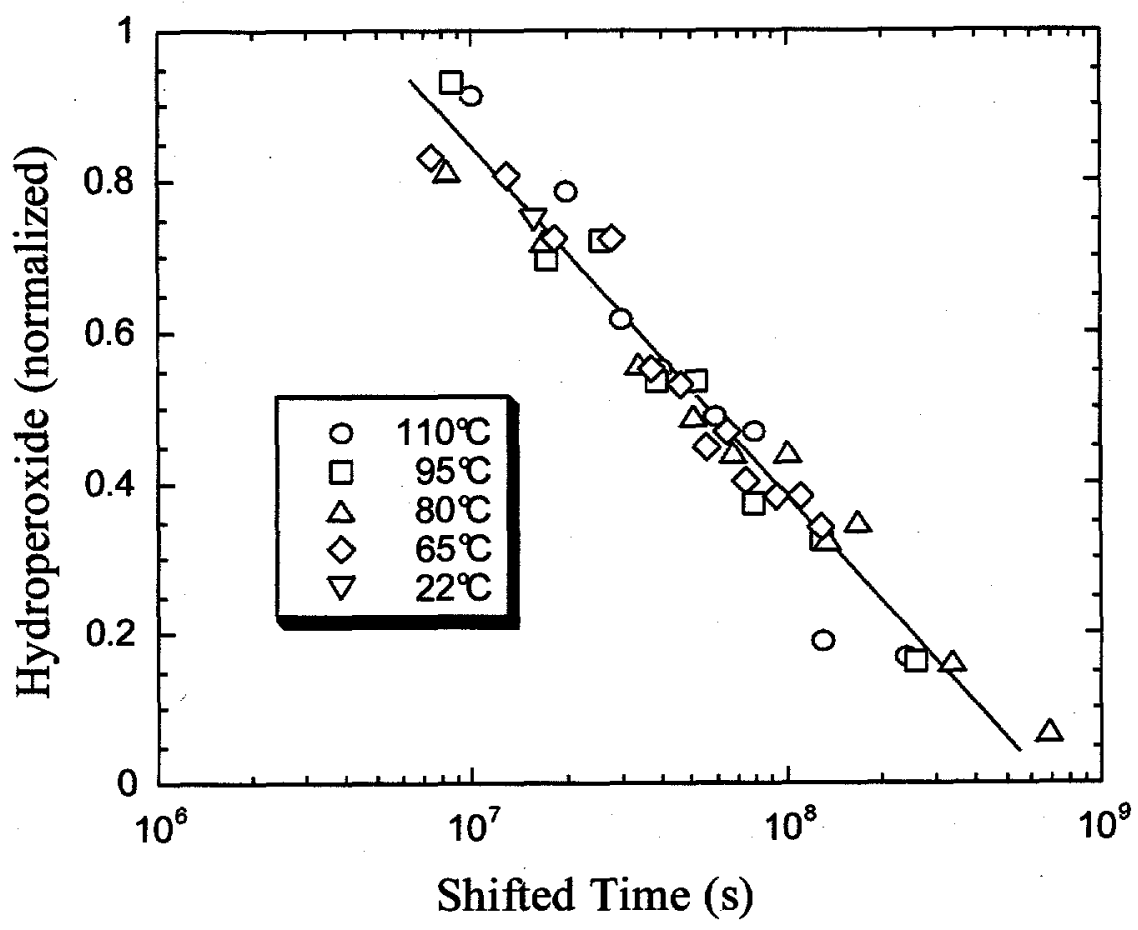




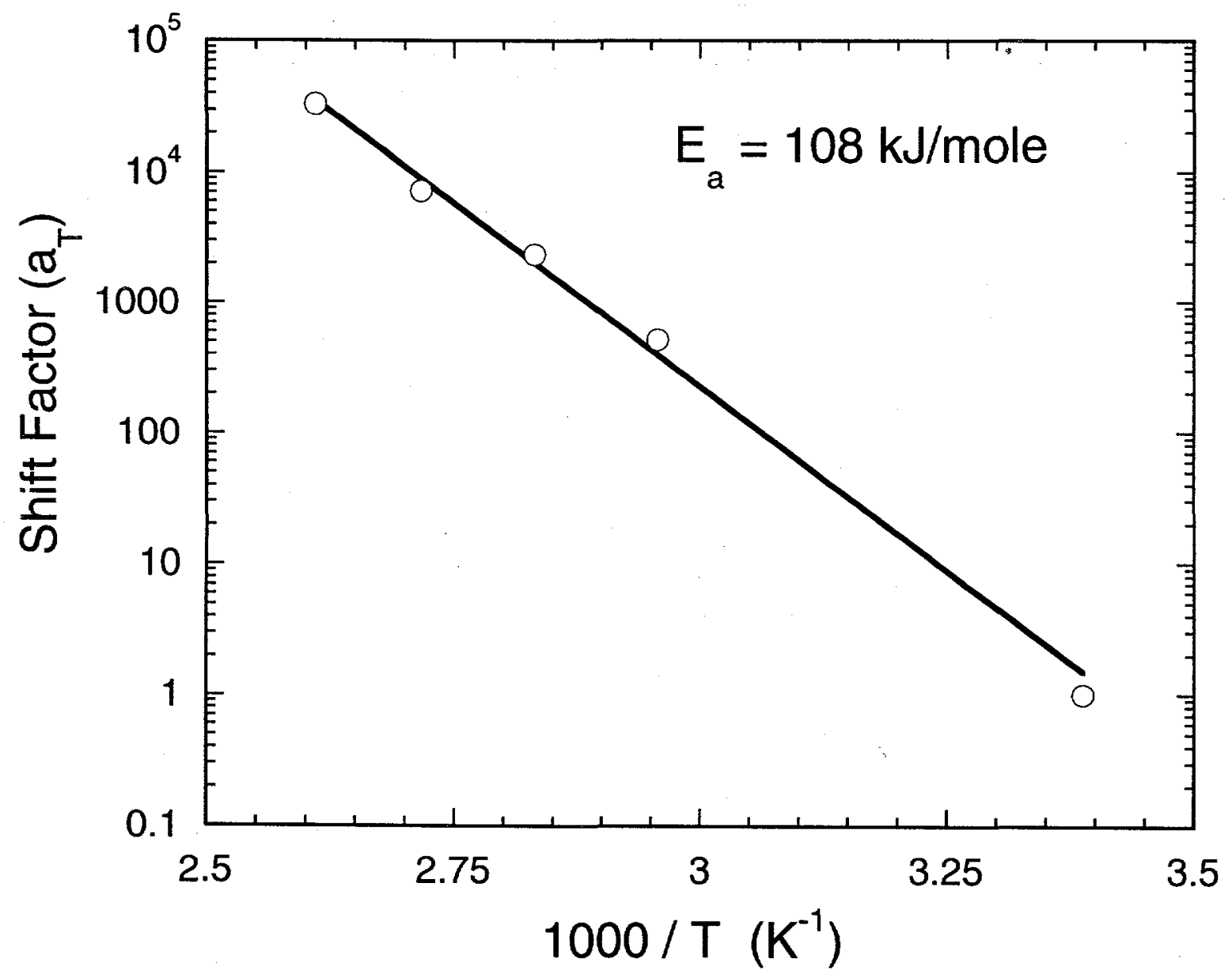



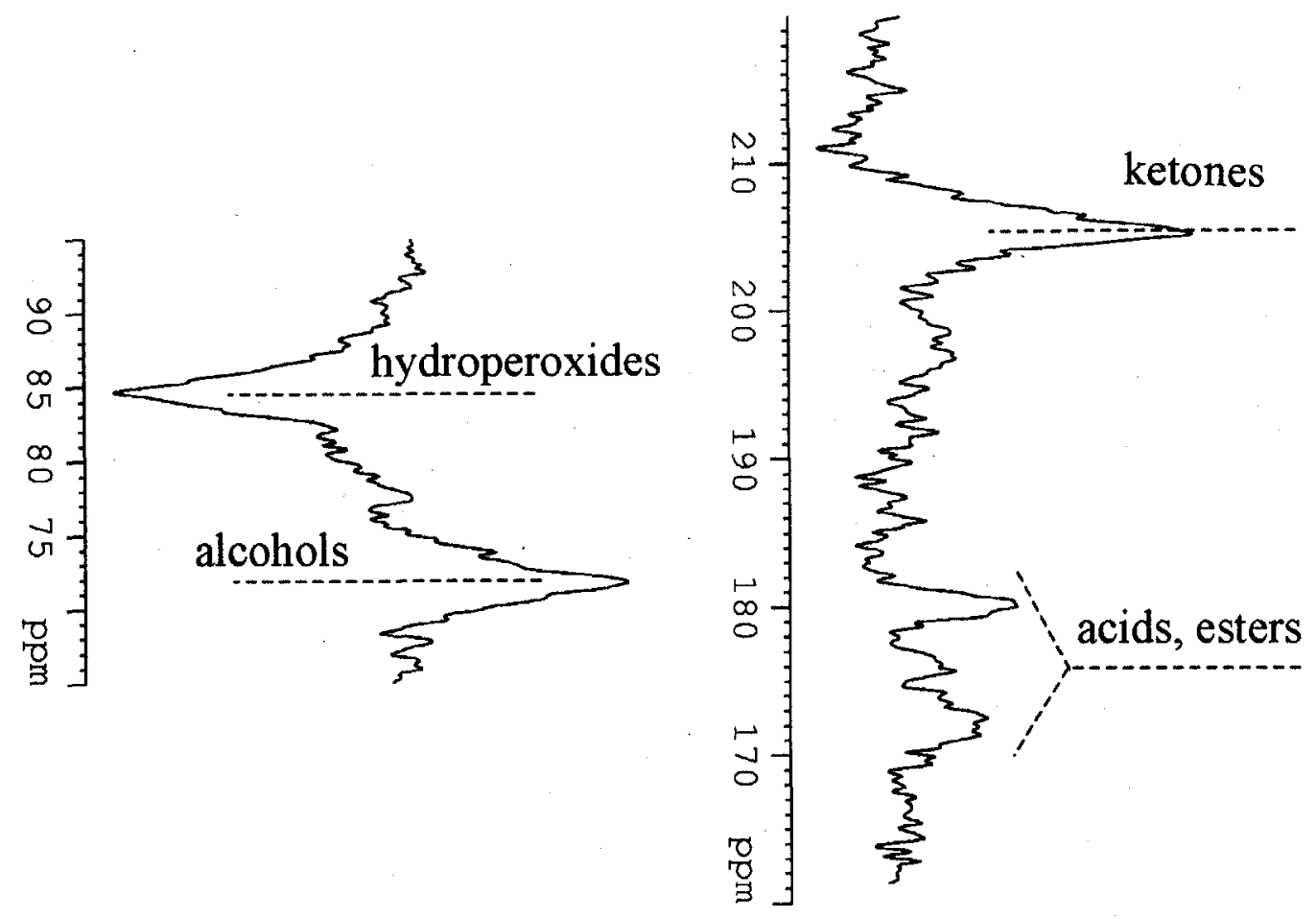

$\stackrel{T}{\sim}$ 


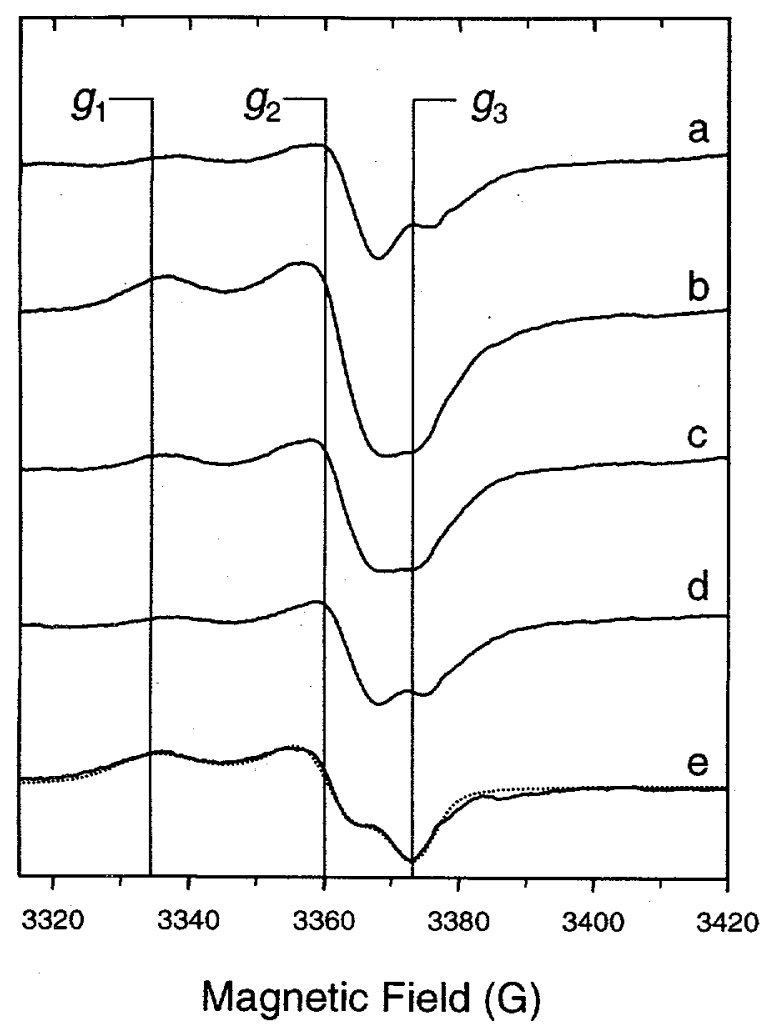

Figure 8. This figure made full scale for the journal. 